\title{
The impact of a $100 \%$ smoke-free law on the health of hospitality workers from the city of Neuquén, Argentina
}

\author{
Veronica Schoj, ${ }_{5}^{1}$ Mariela Alderete, ${ }^{1}$ Ernesto Ruiz, ${ }^{2}$ Santiago Hasdeu, ${ }^{3}$ Bruno Linetzky, \\ Daniel Ferrante ${ }^{5}$
}

1 GRANTAHI (Programa de Control de Tabaco) y Servicio de Medicina Familiar, Hospital Italiano de Buenos Aires, Buenos Aires, Argentina ${ }^{2}$ Hospital Provincial de Neuquén 'Dr. E. Castro Rendón', Neuquén, Argentina ${ }^{3}$ Hospital Centenario 'Dr. Natalio Burd', Neuquén, Argentina ${ }^{4}$ Ministerio de Salud de la Nación, Buenos Aires, Argentina ${ }^{5}$ Fundación GESICA y Ministerio de Salud de la Nación, Buenos Aires, Argentina

\section{Correspondence to}

Veronica Schoj, GRANTAHI (Programa de Control de Tabaco) y Servicio de Medicina Familiar, Hospital Italiano de Buenos Aires, Buenos Aires, Argentina;

vschoj@fibertel.com.ar

Received 1 August 2009

Accepted 23 November 2009

\section{(2) UN LOCK:1}

This paper is freely available online under the BMJ Journals unlocked scheme, see http:// tobaccocontrol.bmi.com/site/ about/unlocked.xhtml

\section{ABSTRACT}

Objectives The objective of this study was to evaluate the impact of $100 \%$ smoke-free environment legislation on respiratory and sensory irritation symptoms and respiratory function among bar and restaurant workers from the city of Neuquén, Argentina.

Methods Pre-ban and post-ban studies without a comparison group in an Argentinean city were conducted. A baseline survey and spirometric measurements were performed with a total of 80 bar and restaurant workers 1 month before (October 2007) and 3 months after (March 2008) the implementation of the new $100 \%$ smoke-free legislation.

Results A significant reduction in secondhand smoke exposure was observed after the enactment and enforcement of the new legislation, and an important reduction in respiratory symptoms (from a pre-ban level of $57.5 \%$ to a post-ban level of only $28.8 \%$ ). The reduction of sensory irritation symptoms was even higher. From $86.3 \%$ of workers who reported at least one sensory irritation symptom in October 2007, only $37.5 \%$ reported the same symptoms in March 2008. Also, data obtained by spirometry showed a significant forced vital capacity increase.

Conclusions Consistent with other studies, 100\% smoke-free legislation improved short-term health outcomes in the sample and should be implemented nationwide. Furthermore, undertaking this study has been highly important in promoting 100\% smoke-free environment legislation at the workplace as a legitimate right of hospitality workers, and in reducing social acceptance of designated smoking areas in bars and restaurants.

\section{INTRODUCTION}

Several Latin American countries, including Uruguay, Panama, Colombia and Guatemala, have passed $100 \%$ smoke-free legislation for bars and restaurants between 2006 and 2008. Argentina and Mexico have introduced subnational policies according to the World Health Organization (WHO) recommended standards, as is the case in Mexico City (2008) and several Argentine provinces and cities (2005-2009).

Argentina has not ratified the WHO Framework Convention on Tobacco Control (FCTC) as of 30 June 2009. However, six provinces (Santa Fe, Tucuman, Neuquén, Cordoba, Mendoza and Entre Ríos) have introduced comprehensive smoke-free laws for public places and workplaces with the inclusion of $100 \%$ smoke-free bars and restaurants, and over 17 cities enacted 100\% smoke-free ordinances in local bars and restaurants between 2006 and 2009.

Exposure to secondhand smoke (SHS) has been associated with an increased risk of respiratory symptoms, ${ }^{1-4}$ lung cancer, ${ }^{56}$ acute coronary syndromes $^{7-10}$ and stroke. ${ }^{11} 12$ Three recent reports have shown the causal relationship between SHS and the increase in disease and death among the people exposed to tobacco smoke. ${ }^{13-15}$

Restaurant and bar workers have a significantly increased risk as they are exposed daily to high doses of tobacco smoke as compared to other workers. ${ }^{16}$

Strong evidence links the implementation of $100 \%$ smoke-free legislation with a reduction of respiratory symptoms and hospital admissions due to myocardial infarction (MI). ${ }^{17}{ }^{18}$ At least six previous studies developed in different regions worldwide (Ireland, Scotland, Norway, and San Francisco, Kentucky and New York in USA) have evaluated respiratory symptoms (with or without functional respiratory tests) before and after the implementation of $100 \%$ smoke-free laws. All of these studies have shown a significant improvement in respiratory symptoms and spirometry measurements. ${ }^{19-24}$

To our knowledge, similar studies have not been conducted in Latin America. Our project has been developed by key organisations members of the Smoke-Free Alliance of Argentina (ALIAR).

The objective of this study was to evaluate the impact of $100 \%$ smoke-free environment legislation on respiratory and sensory irritation symptoms and respiratory function among non-smoking bar and restaurant workers from the city of Neuquén, Argentina.

\section{METHODS \\ Overview}

The city of Neuquén is the capital of the Province of Neuquén, Argentina, located in the Patagonian region. Neuquén has a population of 270000 inhabitants. On 31 August 2007, the city enacted a $100 \%$ smoke-free ordinance, which banned cigarette smoking in all public venues and workplaces, including bars and restaurants. The ordinance entered into force on 15 November 2007.

The study was approved by the ethics committees of the Italian Hospital of Buenos Aires and of the Provincial Hospital of Neuquén 'Dr. E. Castro Rendón'. 


\section{STUDY DESIGN}

We conducted a pre-ban and post-ban study without a comparison group in the city of Neuquén, Argentina.

A baseline survey and spirometric measurements were performed 1 month before (October 2007) and 3 months after (March 2008) the implementation of the new legislation in bar and restaurant workers. We also evaluated non-workplace exposure to SHS in the home and in other public places.

\section{Recruitment of bars and restaurants}

We obtained a list of the total number and locations of all 101 bars and restaurants in the city (52 restaurants and 49 bars) and invited all of them to participate. Each bar and restaurant owner was contacted by invitation letter, describing the study and assuring confidentiality and anonymity. Once the owner agreed to participate, we requested their permission to visit the venue and recruit workers for the study. A total of 83 venues agreed to participate; 5 refused participation, 5 had voluntary $100 \%$ smoke-free policies at the beginning of the study, 3 were about to finish their commercial activity and 5 small bars were excluded because they did not meet the inclusion criteria (all workers were smokers). From the 83 venues that agreed to participate in our study, 12 were not finally included due to operative problems with complete evaluation of workers (they were not available to complete the survey on at least 3 visits to the venue). Finally, 71 venues ( $73.1 \%$ of all) were included and completed the study.

\section{Participant selection}

All workers from 71 bars and restaurants were invited to participate in the study. Smoking and non-smoking workers completed the baseline survey. After the first interview smokers were excluded from the study and did not undergo any further testing (sensory and respiratory symptoms and spirometry). Participants were requested to provide written informed consent before inclusion and were assured about the confidentiality and anonymity of their answers. Inclusion criteria were: nonsmoking waiters working for $25 \mathrm{~h}$ or more per week for at least 3 months before the beginning of the study, and non-smokers who had quit smoking at least 6 months before the study. Current smokers only completed the baseline survey. Asthmatic workers were also included for a specific subgroup evaluation and were requested to complete the same questionnaire. Temporary workers were excluded from the study.

\section{Interviews}

All participants were invited to complete two interviews, conducted by a single study investigator. A baseline interview and a spirometry test (both performed at the workplace) were conducted in October 2007 and a second one in March 2008, 1 month before and 3 months after the implementation of the new legislation.

We developed and adapted the Spanish version of the International Union Against Tuberculosis and Lung Disease (IUATLD) Bronchial Symptoms Questionnaire used by Eisner et al in a study conducted at the University of San Francisco. ${ }^{21}$ This instrument has also been used in several other studies. ${ }^{25} \mathrm{We}$ assessed face validity of the Spanish version of the questionnaire. ${ }^{26}$ We then developed a pilot evaluation in 20 waiters to define the Argentinean version of the questionnaire.

Questions regarding respiratory symptoms included cough, phlegm production, wheezing and dyspnoea. Sensory irritation symptoms included red, teary, or irritated eyes; sore and scratchy throat, sneezing and running nose. Questions regarding asthma and asthma-like symptoms included history of asthma, asthma episodes during the last 4 weeks and any current asthma medication. ${ }^{26}$

At both interviews, participants were also asked about their attitudes towards SHS and about the implementation of the new smoke-free legislation. In addition, we evaluated whether they were aware of the harm caused by SHS, and the amount of SHS exposure at work and at home.

Lung function was measured with a portable spirometer. As stated in internationally accepted protocols, each participant underwent at least three forced expiratory manoeuvers. ${ }^{27} 28 \mathrm{We}$ also measured the forced expiratory volume in $1 \mathrm{~s}\left(\mathrm{FEV}_{1}\right)$ and forced vital capacity (FVC). Results were expressed as percentages of the predicted values.

\section{Statistical analysis}

Categorical data were described as frequencies and percentages. Continuous data were described as mean (SD) or median (IOR).

We used the Wilcoxon signed rank test and the Student t test for normally distributed and non-normally distributed continuous paired variables respectively. Categorical variables were compared between groups using a McNemar $\chi^{2}$ test. Estimation of the sample size revealed that a minimum of 75 workers with some kind of respiratory or sensory irritation symptom after prohibition should be included to obtain an $80 \%$ power ( $\alpha$ error $5 \%, 2$-tailed). We considered a potential 30\% drop-out rate at follow-up. ${ }^{24}$ Therefore the number of participants necessary to be recruited for this study was 98 .

In the analysis we only included those participants who completed the survey and underwent spirometry before and after smoking prohibition. We assessed normality with data distribution.

Primary endpoints included the percentage of workers with pre-ban and post-ban respiratory and sensory irritation symptoms, and the $\mathrm{FEV}_{1} / \mathrm{FVC}$ ratio change per spirometry reading of all participants before and after the implementation of the new legislation. A p value of less than 0.05 was considered significant for all analyses. Data were analysed using STATA V.10.0 (College Station, Texas, USA) and SPSS V.13.0 (SPSS, Chicago, Illinois, USA).

\section{RESULTS}

\section{Bar and restaurant worker characteristics}

Of the 198 workers included in the study from 88 bars, 64 were smokers (32.6\%) and 134 non-smokers (67.4\%). Smoking workers completed the baseline interview but did not undergo any further measurement. From the 134 non-smoking workers, 114 completed the spirometry; 20 participants were not available at their workplace the second time we visited the venues to perform the follow-up test. A total of 26 workers were lost at follow-up due to the fact that their workplaces had closed or because they had quit their jobs at the time of the post-ban visit. Eight participants did not undergo spirometry due to operative problems. Post-ban interview and spirometry were completed in 80 participants.

Of the total number of participants, 31 (38.7\%) were women and $5(6.2 \%)$ had a history of asthma (self-reported). The mean age of participants was $34.3 \pm 12.5$ years with an average of $11.0 \pm 2.3$ years of education. Study participants worked an average of $50.7 \pm 13.4 \mathrm{~h}$ per week and $47.5 \%$ had at least one evening shift. The mean duration of employment at the current workplace was $4(1-6)$ years (table 1$)$. 
Table 1 Baseline characteristics of non-smoking participants $(n=80)$

\begin{tabular}{lc}
\hline Parameter & Value \\
\hline Mean age, years & $34.3 \pm 12.5$ \\
No. (\%) of women, $\mathrm{n}(\%)$ & $31(38.7)$ \\
Education, years & $11.0 \pm 2.3$ \\
History of asthma*, $\mathrm{n}(\%)$ & $5(6.2 \%)$ \\
Hours worked in current job/week & $50.7 \pm 13.4$ \\
At least one evening shift/week, $\mathrm{n}(\%)$ & $38(47.5 \%)$ \\
Time working in current job, years & $4(1-6)$ \\
\hline Values are mean \pm SD or median (IQR). & \\
${ }^{*}$ Self-reported and those on asthma medication. &
\end{tabular}

The age (median 25, IOR 20 to $32, \mathrm{p}=0.04$ ) and duration of employment (median 1.5, IOR 0.25 to $3, p=0.001$ ) of those workers who did not complete the follow-up were lower as compared to those who completed the second spirometry.

\section{Smoke exposure and associated respiratory and sensory irritation symptoms}

Non-workplace (exposure in the home and in public places) and workplace exposure are reported separately.

We found a median of $1 \mathrm{~h}$ (range $0-2 \mathrm{~h}$ ) of non-workplace exposure/day before the enforcement of the new legislation. This figure decreased to a median of $0 \mathrm{~h}$ /day (range $0-2 \mathrm{~h}$ /day) post ban. We observed a small but statistically significant difference using a non-parametric test (Wilcoxon signed rank test).

We observed a significant reduction in SHS exposure post ban. A month before the implementation of the law, hospitality workers reported a median of $8 \mathrm{~h} /$ day (IOR 8 to $9 \mathrm{~h}$ ) smoke exposure at their workplaces. This figure dropped to $0 \mathrm{~h}$ (IOR 0 to 0$) 3$ months after smoking prohibition $(p<0.001)$ (table 2$)$. Participants worked an average of $51.4 \pm 13.0 \mathrm{~h} /$ week. This figure remained the same after smoking prohibition.

We observed an important reduction in respiratory symptoms (from a pre-ban level of $57.5 \%$ to a post-ban level of only $28.7 \%$ $(p<0.001))$. Table 2 shows the respiratory symptoms that declined

Table 2 Pre-ban and post-ban workplace and non-workplace exposure and respiratory and sensory irritation symptoms in bar and restaurant workers

\begin{tabular}{|c|c|c|c|}
\hline & Pre-ban exposure & Post-ban exposure & p Value \\
\hline $\begin{array}{l}\text { Workplace tobacco smoke } \\
\text { exposure, h/day (IOR) }\end{array}$ & $8(8-9) \mathrm{h} /$ day & $0(0-0) \mathrm{h} /$ day & $<0.001$ \\
\hline $\begin{array}{l}\text { Non-workplace tobacco smoke } \\
\text { exposure, h/day (IQR) }\end{array}$ & $1(0-2) \mathrm{h} /$ day & $0(0-2) \mathrm{h} / \mathrm{day}$ & 0.0008 \\
\hline \multicolumn{4}{|l|}{ Respiratory symptoms } \\
\hline At least one symptom, \% (n) & $57.5 \%(46)$ & $28.7 \%(23)$ & $<0.001$ \\
\hline Cough, \% (n) & $20.2 \%(16)$ & $7.1 \%(5)$ & 0.039 \\
\hline $\begin{array}{l}\text { Wakes during sleep due to } \\
\text { cough, \% (n) }\end{array}$ & $31.6 \%(25)$ & $8.8 \%(7)$ & $<0.001$ \\
\hline Phlegm production, \% (n) & $19.4 \%(15)$ & $15 \%(12)$ & 0.454 \\
\hline Wheezing, \% (n) & $7.5 \%(6)$ & $3.7 \%(3)$ & 0.453 \\
\hline Tightness in chest, \% (n) & $17.5 \%(14)$ & $7.5 \%(6)$ & 0.039 \\
\hline Dyspnoea on exertion, \% (n) & $41.2 \%(33)$ & $16.2 \%(13)$ & $<0.001$ \\
\hline Dyspnoea at rest, \% (n) & $21.2 \%(17)$ & $5 \%(4)$ & 0.001 \\
\hline \multicolumn{4}{|l|}{ Sensory irritation symptoms } \\
\hline At least one symptom, \% (n) & $86.3 \%(69)$ & $37.5 \%(30)$ & $<0.001$ \\
\hline Red eyes, \% (n) & $58 \%(46)$ & $20 \%(16)$ & $<0.001$ \\
\hline Sneezing, \% (n) & $58.2 \%(46)$ & $26.2 \%(21)$ & $<0.001$ \\
\hline Scratchy throat, \% (n) & $53.1 \%(42)$ & $17.7 \%(14)$ & $<0.001$ \\
\hline
\end{tabular}

after prohibition, such as cough, cough at night, dyspnoea on exertion and at rest, and tightness in the chest.

The reduction of sensory irritation symptoms was even greater. From $86.3 \%$ of workers who reported at least one sensory irritation symptom in October 2007, only $37.5 \%(\mathrm{p}<0.001)$ reported the same symptoms in March 2008 (table 2).

\section{Pulmonary function}

Prohibition of smoking was associated with an improved pulmonary function. We found a significant improvement in FVC (mean 96, SD 12 to 88). We did not find any significant differences in $\mathrm{FEV}_{1}$ measurements (mean 90, SD 17 to 70) (table 3).

\section{Workers' attitudes towards the new legislation}

A month before prohibition, $91.2 \%$ of participants reported knowledge of the legislation. After the implementation of the law, knowledge increased to $98.7 \%(\mathrm{p}=0.07)$.

Support for the new legislation was high and did not change before and after the enforcement of the law $(93.8 \%$ and $96.4 \%$, respectively).

Data collected from the baseline interview showed that 89.8 $\%$ of workers were in favour of the smoke-free legislation. Support to $100 \%$ smoke-free legislation was $93.1 \%$ in nonsmoking and $82.8 \%$ in smoking workers.

\section{DISCUSSION}

The main finding of our study is that the implementation of the new legislation was associated with a substantial and rapid reduction of respiratory and sensory irritation symptoms. Furthermore, there was a significant improvement in the respiratory function of participants as stated in other studies. ${ }^{19-24} 2930$

Most of our sample included healthy participants with normal spirometric results at baseline; however, symptom reduction and improvement in spirometry measurements were associated with a dramatic reduction in secondhand smoke exposure at work reported by workers.

Although we observed a statistically significant reduction in non-workplace exposure to SHS, clinically, it represents a very small reduction as compared to the drastic workplace reduction. Thus, clinical and spirometric changes in non-smoking workers are mainly attributable to the reduction of workplace exposure to SHS

Also, our study shows a statistically and clinically significant increase in FVC after the removal of SHS exposure like several other studies published elsewhere. Furthermore, this change was observed in a very short period of time.

Another important finding of this study is the high level of support for the new $100 \%$ smoke-free law observed among smoking and non-smoking workers. We obtained similar results in a national survey conducted in 13 Argentine cities, where there was a $96 \%$ support to $100 \%$ smoke-free legislation in the general (smoking and non-smoking) population. ${ }^{31}$

To our knowledge, this is the first study to show the positive impact of the implementation of $100 \%$ smoke-free legislation in the workplace on the health of hospitality workers in Latin America.

Table 3 Pulmonary function in bar and restaurant workers

\begin{tabular}{lllr}
\hline Measurement & Baseline media (SD) & Post-law media (SD) & p Value \\
\hline FEV $_{1}$ & $90 \%(11 \%$ to $63 \%)$ & $90 \%(17 \%$ to $70 \%)$ & 0.8372 \\
FVC & $88 \%(11 \%$ to $55 \%)$ & $96 \%(12 \%$ to $88 \%)$ & $<0.001$ \\
\hline
\end{tabular}

$\mathrm{FEV}_{1}$, forced expiratory volume in $1 \mathrm{~s}$; FVC, forced vital capacity. 


\section{What this paper adds}

- This study confirms that $100 \%$ smoke-free environments have a positive effect on hospitality workers' respiratory health in Latin America, and in many other countries worldwide as it has been shown in previous studies.

- The study also provides local data helpful to raise awareness among decision makers regarding the need for $100 \%$ smokefree environment legislation without designated smoking areas to protect the health of hospitality workers and to counteract the tobacco industry's attempts to implement Courtesy of Choice and Accommodation programmes.

\section{LIMITATIONS}

The use of self-reporting without a biological marker could contribute to potential bias of the results. However, this is not likely to be related to the lack of support for the new legislation, as most workers were in favour of $100 \%$ smoke-free workplaces. The non-response rate and significantly high follow-up dropout rate could also produce a selection bias. This was an expected result also observed in other studies, and may be caused by the constant changes among workers in the hospitality business as compared to other variables.

\section{CONCLUSIONS}

Consistent with other studies, 100\% smoke-free legislation improved short-term health outcomes in our sample and should be implemented nationwide in Argentina. Furthermore, the undertaking of this study has been greatly important in promoting $100 \%$ smoke-free environment legislation in the workplace as a legitimate right of hospitality workers, and to reduce social acceptance of designated smoking areas in bars and restaurants. Media coverage of the study results has also had a great impact countrywide and several legislators have used this evidence as the basis of bills.

Acknowledgements We wish to thank Lorena Allemandi for the preparation of this manuscript, Dr Marita Pizzarro, respiratory doctor, for her collaboration in the interpretation of spirometric results, Dr Julian Ciruzzi and respiratory technicians Daniel Schiro and Claudia Toia, who performed the spirometric measurements. We also wish to thank all bar and restaurant workers from the city of Neuquén for their kind and committed participation.

Funding M Bloomberg Foundation.

\section{Competing interests None.}

Ethics approval This study was conducted with the approval of the Hospital Italiano de Buenos Aires and Hospital Provincial de Neuquén's ethical committees.

\section{Patient consent Obtained.}

Provenance and peer review Not commissioned; externally peer reviewed.

\section{REFERENCES}

1. Leuenberger $\mathbf{P}$, Schwartz J, Ackermann-Liebrich U, et al. Passive smoking exposure in adults and chronic respiratory symptoms (SAPALDIA Study). Swiss Study on Air Pollution and Lung Diseases in Adults, SAPALDIA Team. Am J Respir Crit Care Med 1994;150(5 Pt 1):1222-8.

2. Radon K, Busching K, Heinrich J, et al. Passive smoking exposure: a risk factor for chronic bronchitis and asthma in adults? Chest 2002;122:1086-90.

3. Simoni M, Baldacci S, Puntoni R, et al. Respiratory symptoms/diseases and environmental tobacco smoke (ETS) in never smoker Italian women. Respir Med 2007;101:531-8.
4. Zemp E, Elsasser S, Schindler C, et al. Long-term ambient air pollution and respiratory symptoms in adults (SAPALDIA study). The SAPALDIA Team. Am J Respir Crit Care Med 1999;159(4 Pt 1):1257-66.

5. Brennan P, Buffler PA, Reynolds P, et al. Secondhand smoke exposure in adulthood and risk of lung cancer among never smokers: a pooled analysis of two large studies. Int J Cancer 2004;109:125-31.

6. Zhong L, Goldberg MS, Parent ME, et al. Exposure to environmental tobacco smoke and the risk of lung cancer: a meta-analysis. Lung Cancer 2000;27:3-18.

7. McElduff P, Dobson AJ, Jackson R, et al. Coronary events and exposure to environmental tobacco smoke: a case-control study from Australia and New Zealand. Tob Control 1998; 7:41-6.

8. Pitsavos C, Panagiotakos DB, Chrysohoou C, et al. Association between exposure to environmental tobacco smoke and the development of acute coronary syndromes: the CARDI02000 case-control study. Tob Control 2002:11:220-5.

9. Rosenlund M, Berglind N, Gustavsson A, et al. Environmental tobacco smoke and myocardial infarction among never-smokers in the Stockholm Heart Epidemiology Program (SHEEP). Epidemiology 2001;12:558-64.

10. He J, Vupputuri S, Allen K, et al. Passive smoking and the risk of coronary heart disease-a meta-analysis of epidemiologic studies. $N$ Engl J Med 1999; 340:920-6.

11. Bonita R, Duncan J, Truelsen T, et al. Passive smoking as well as active smoking increases the risk of acute stroke. Tob Control 1999;8:156-60.

12. Iribarren C, Darbinian J, Klatsky AL, et al. Cohort study of exposure to environmental tobacco smoke and risk of first ischemic stroke and transient ischemic attack. Neuroepidemiology 2004;23(1-2):38-44.

13. US Department of Health and Human Services. The health consequences of involuntary exposure to tobacco smoke: a report of the Surgeon General. Washington, DC: US Department of Health and Human Services, Centers for Disease Control and Prevention, Coordinating Center for Health Promotion, National Center for Chronic Disease Prevention and Health Promotion, Office on Smoking and Health, 2006.

14. State of California, AIR RESOURCES BOARD, APPENDIX III. 'Proposed identification of environmental tobacco smoke as a toxic air contaminant'. 2005.

15. World Health Organization, International Agency for Research on Cancer. Monographs on the evaluation of carcinogenic risks to humans. Vol. 83. Tobacco smoke and involuntary smoking. Genva: World Health Organization, International Agency for Research on Cancer (IARC), 2002.

16. Siegel M, Skeer M. Exposure to secondhand smoke and excess lung cancer mortality risk among workers in the " 5 B's": bars, bowling alleys, billiard halls, betting establishments, and bingo parlours. Tob Control 2003;12:333-8.

17. Sargent RP, Shepard RM, Glantz SA, et al. Reduced incidence of admissions for myocardial infarction associated with public smoking ban: before and after study. BMJ 2004;328:977-80.

18. Pell JP, Haw S, Cobbe $S$, et al. Smoke-free legislation and hospitalizations for acute coronary syndrome. N Engl J Med 2008;359:482-91.

19. Allwright S, Paul G, Greiner B, et al. Legislation for smoke-free workplaces and health of bar workers in Ireland: before and after study. BMJ 2005;331:1117.

20. Eagan TM, Hetland J, Aaro LE. Decline in respiratory symptoms in service workers five months after a public smoking ban. Tob Control 2006;15:242-6.

21. Eisner MD, Smith AK, Blanc PD. Bartenders' respiratory health after establishment of smoke-free bars and taverns. JAMA 1998;280:1909-14.

22. Farrelly MC, Nonnemaker JM, Chou R, et al. Changes in hospitality workers exposure to secondhand smoke following the implementation of New York's smoke-free law. Tob Control 2005;14:236-41.

23. Goodman P, Agnew M, McCaffrey $M$, et al. Effects of the Irish smoking ban on respiratory health of bar workers and air quality in Dublin pubs. Am J Respir Crit Care Med 2007:175:840-5.

24. Menzies D, Nair A, Williamson PA, et al. Respiratory symptoms, pulmonary function, and markers of inflammation among bar workers before and after a legislative ban on smoking in public places. JAMA 2006;296:1742-8.

25. Burney PG, Laitinen LA, Perdrizet $S$, et al. Validity and repeatability of the IUATLD (1984) Bronchial Symptoms Questionnaire: an international comparison. Eur Respir J 1989;2:940-5

26. Anon. [European study on asthma. Prevalence of bronchial hyperreactivity and asthma in young adults from 5 Spanish areas. Spanish Group of the European Study on Asthma]. Barcelona, Spain: Med Clin 1996;106:761-7.

27. Miller MR, Hankinson J, Brusasco V, et al. Standardisation of spirometry. Eur Respir J 2005;26:319-38.

28. Anon. Standardization of spirometry, 1994 update. American Thoracic Society. Am J Respir Crit Care Med 1995;152:1107-36.

29. Larsson M, Boethius G, Axelsson S, et al. Exposure to environmental tobacco smoke and health effects among hospitality workers in Sweden-before and after the implementation of a smoke-free law. Scand J Work Environ Health 2008; 34:267-77.

30. Hahn EJ, Rayens MK, York N, et al. Effects of a smoke-free law on hair nicotine and respiratory symptoms of restaurant and bar workers. J Occup Environ Med 2006; 48:906-13

31. Schoj VLB. Population-based survey to assess the impact of $100 \%$ smoke-free environments in Argentina - Alianza libre de humo de tabaco - Argentina. 2008. http://www.aliarargentina.org paper under elaboration 2008. 